УДК 330.322

JEL E22,O33

DOI: $10.17213 / 2312-6469-2021-2-112-119$

\title{
ПРОБЛЕМЫ ФОРМИРОВАНИЯ ИНВЕСТИЦИОННОГО КЛИМАТА В СФЕРЕ ОБОРОННО-ПРОМЫШЛЕННОГО КОМПЛЕКСА В УСЛОВИЯХ ЦИФРОВОЙ ЭКОНОМИКИ
}

\author{
(ㄷ Д.А. Сингилевич*, В.Д. Секерин 2021 \\ "Экспертный совет Комитета Государственной Думы Российской \\ Федерации по обороне, г. Москва, Россия \\ **:Институт проблем управления им. В.А. Трапезникова РАН \\ 2. Москва, Россия
}

В статье рассмотрены структура инвестищионного климата, проблемь его формирования в оборонно-промышленном комплексе и их взаимосвязь с основными факторами, влияющими на формирование инвестиционного климата, структура и направления инвестиционной политики.

Ключевые слова: структура инвестиционного климата, проблемное поле, инвестиционные факторы, инвестиционная политика, инвестиционный климат, обороннопромышленный комплекс, нормы права.

\section{PROBLEMS OF FORMING THE INVESTMENT CLIMATE IN THE MILITARY-INDUSTRIAL COMPLEX IN THE DIGITAL ECONOMY}

\author{
(C) D.A. Singilevich*, V.D. Sekerin ${ }^{* *} 2021$
}

Expert Council of the State Duma Committee on Defense, Moscow, Russia V.A. Trapeznikov Institute of Control Sciences RAS, Moscow, Russia

The article considers the structure of the investment climate, the problems of its formation in the military-industrial complex and their relationship with the main factors influencing the formation of the investment climate, the structure and directions of investment policy.

Keywords: structure of the investment climate, problem field, investment factors, investment policy, investment climate, military-industrial complex, legal norms.

Большое количество определений термина «инвестиционный климат», существующее на сегодняшний день, а также способов определения его состояния, рассматриваются в первую очередь с позиции потенциальной прибыли от вложенных средств $[7,12]$. 
Как правило, под инвестиционным климатом понимается среда, в которой протекают инвестиционные процессы [9]. На формирование инвестиционного климата оказывает влияние взаимосвязанный комплекс политических, организационно-правовых, экономических, социальных и других факторов, которые характеризуют условия инвестирования в определенной стране или отрасли экономики $[6,11]$.

Вместе с тем современная структура инвестиционного климата наряду с объективными факторами включает: эффективность инвестиционной деятельности, инвестиционные активность, привлекательность, потенциал и риск $[2,5]$.

Оборонно-промышленный комплекс в силу своего предназначения и содержания является очень специфической отраслью экономики государства. Отраслью, которая требует особого внимания и постоянного контроля. Высокотехнологичная продукция ОПК, как предназначенная исключительно для Вооруженных Сил, так и двойного назначения реализуется на рынке в условиях жесткой конкуренции, что определяет строжайшие требования к её производству и продвижению $[1,3]$. На сегодняшний день создан мощный корпоративный базис ОПК, который включает 65 интегрированных структур, концентрирующих более $80 \%$ производства продукции, при этом треть выпускаемой продукции - продукция двойного назначения.

Учитывая, что основным заказчиком и потребителем продукции ОПК является государство, факторы, оказывающие влияние на формирование инвестиционного климата и проявляющиеся при этом проблемы, относительно оборонно-промышленного комплекса необходимо рассматривать в ином ракурсе [8].

Раскроем содержание вышеназванных факторов, влияющих на формирование инвестиционного климата в сфере ОПК:

- политические, а именно политика государства и качество управленческой деятельности - деятельность руководства страны по обеспечению национальной безопасности, от правительства зависят соблюдение прав собственности, государственное регулирование и налоговая политика, инфраструктуры работы финансовых и ресурсных рынков, а также общие факторы, которые определяют качество управления государства. Для зарубежных инвесторов важным условием является отсутствие международных санкций;

- организационно-правовые, включают: управленческий - вопросы организации, планирования и контроля инвестиционной деятельности; правовой - вопросы установления и строгого соблюдения правовых норм при осуществлении инвестиционной деятельности; маркетинговый - вопросы создания и продвижения на рынке инвесторов привлекательного образа (имиджа) государства (отрасли, экономики в целом); 
- экономические: обеспечиваются соотношением возможностей государства по поддержанию и развитию ОПК в соответствии с потребностями военной организации страны с привлечением инвесторов; зависят от емкости существующего национального и мирового рынков и возможности их расширения; включают условия сбыта и уровня цен на продукцию и услуги ОПК, услуги на национальном и международном рынках, а также позиции поставщиков-конкурентов; нивелируются экономической политикой руководства страны по развитию инвестируемых направлений деятельности ОПК и т.д.

К факторам, также обеспечивающим формирования инвестиционного климата в сфере ОПК безусловно относятся:

- инновационно-производственный, характеризующий уровень развития науки и внедрения современных технологий, состояние производственной сферы и культуру производства ОПК в целом или конкретного кластера в нем;

- кадровый, показывающий наличие квалифицированной рабочей силы, обладающей требуемым профессионально-образовательным уровнем.

Приведенные факторы в случае несоответствия их требуемым параметрам (перехода их в отрицательную область значений) обуславливают проблемы при формирования благоприятного инвестиционного климата, становятся причинами их возникновения [4].

В настоящее время в сводном реестре организаций обороннопромышленного комплекса (ОПК) 1355 организаций. К ОПК отнесены предприятия, как входящие в те или иные кластеры («Объединённая авиастроительная корпорация», «Объединённая судостроительная корпорация», Концерн ВКО «Алмаз-Антей» и др.), так и являющиеся системообразующими компаниями («Уралвагонзавод»,) или достаточно самостоятельными производственными структурами (Казанский вертолетный завод), создающими уникальную продукцию и занимающими на рынке вооружений и военной (специальной) техники (далее - ВВ(C)Т) собственную нишу [10]. Как правило все эти предприятия имеют или планируют получить государственный оборонный заказ (далее - ГОЗ).

Вместе с тем на рынке ВВ(C)Т присутствует достаточно большое количество производителей, которые не получают ГОЗ, не входят в кластеры и производят продукцию не только военного, но и двойного или полностью гражданского предназначения.

В свою очередь их можно разделить на две группы:

- организации, представляющие собой реорганизованные и сумевшие удержаться «на плаву» в 90-е годы советские научнопроизводственные объединения (далее - НПО) и научно-исследовательские институты (НИИ); 
- созданные молодыми предпринимателями в начале 2000-х сравнительно небольшие производственные компании, использующие в своей деятельности самые современные технологии.

Названные организации занимают достаточно узкопрофильные ниши рынка $\mathrm{BB}(\mathrm{C}) \mathrm{T}$ : системы связи и управления, аппаратура для шифрования, спецсредства для правоохранительных структур, специализированное огнестрельное вооружение, оптические приборы, робототехнические комплексы, средства индивидуальной бронезащиты.

Большинство данных производителей ежегодно участвует в Международном военно-техническом форуме «Армия-20ХХ» (с 2015 года проводится ежегодно), в каталогах которого можно ознакомиться с их продукцией.

По некоторым позициям изготавливаемой номенклатуры изделий, они являются конкурентами организаций - получателей ГОЗ: связь, средства защиты, медицинские комплекты. По ряду других позиций - единственными производителями уникальных систем вооружения.

Вместе с тем установленный в России порядок принятия на вооружение образцов ВB(C)Т оставляет мало шансов небольшим, но высокотехнологичным фирмам на получение заказов непосредственно от Минобороны России. Их услугами пользуются, как правило, федеральные органы исполнительной власти, в которых есть свои воинские формирования и спецподразделения - ФСБ, МВД, ФСО, Росгвардия, ФСИН, МЧС. Для принятия на вооружение или закупки своим подразделениям не предусмотренных штатами образцов $\mathrm{BB}(\mathrm{C}) \mathrm{T}$ в названных федеральных органах более действует упрощенный порядок, обусловленный объемами заказа, спецификой поставляемых изделий и рядом других особенностей.

Важно отметить, что независимо от ведомственной принадлежности, для принятия на вооружение $\mathrm{BB}(\mathrm{C}) \mathrm{T}$ издаются соответствующие акты Правительства Российской Федерации.

При этом необходимо понимать, что объем заказов и номенклатура BВ(C)Т, поставляемых Вооруженным Силам Российской Федерации, многократно превышает объемы для других федеральных органов. В силу чего фирмы-поставщики уникального вооружения даже при подключении всех возможностей не смогут обеспечить требуемый объем поставок.

Вместе с тем Минобороны России в случае необходимости может заказать и принять на вооружение требуемое изделие (образец $\mathrm{BB}(\mathrm{C}) \mathrm{T})$ без проведения комплекса испытаний в случае, если оно состоит на вооружении в каком-либо федеральном органе. Так, например в 2015 году на вооружение военной полиции Министерства обороны Российской Федерации были приняты спецсредства (наручники, газовые баллончики, резиновые палки, светошумовые гранаты, защитное снаряжение и др.), состоящие на вооружении подразделений Росгвардии. 
Проблема производственных мощностей касается и выпуска основных видов ВВ(С)Т: танков, самолетов, вертолетов, кораблей, средств ПВО. При наличии принятых на вооружение образцов, неоднократно переносятся сроки поставок в войска танков «Армата», самолетов СУ-57, комплексов ПВО С-500. Количество ракетных комплексов «Искандер» тоже недостаточно для перевооружения всех ракетных бригад в Вооруженных Силах.

Проблема инновационного потенциала при этом характерна в большей для крупных корпораций и концернов, для которых внедрение новых технологий и техническое перевооружение связаны со значительными затратами. В отличие от них небольшие фирмы, занимающие узкие ниши на рынке вооружений могут позволить себе более активное внедрение инноваций, что обеспечивает их конкурентоспособность и формирует благоприятный инвестиционный климат.

Проблемой организационного характера является невысокий уровень подготовки управленческих кадров на предприятиях ОПК, которые не в состоянии решать вопросы организации, планирования и контроля согласно современным требованиям, в том числе и на тех предприятиях, где контрольный пакет акций находится у государства. Такие «эффективные менеджеры», пришедшие в ОПК из других отраслей народного хозяйства, зачастую не понимают специфики отрасли. В результате чего после получения финансирования от заказчика, при отсутствии внятных и объективных причин, производство функционирует с перебоями, поставки смежникам срываются, персоналу не выплачивается заработная плата. Как итог - невыполнение ГОЗ и потеря имиджа надежного поставщика. При ухудшении ситуации возможно банкротство предприятия.

Утрата репутации надежного поставщика качественной продукции приводит к уменьшению количества желающих инвестировать в отрасль. Причиной данной проблемы являются, во-первых, неудовлетворительное качество маркетинговой деятельности, неэффективное использование маркетинговых коммуникаций при продвижении продукции на внешнем и внутреннем рынке и послепродажном её сопровождении (поставка техники в страны Азии и Африки без ее дальнейшего обслуживания), во-вторых, непрофессиональное использование закупленного ВВ(C)Т которые приводят к их утрате при попытке применить по назначению (применение САР танков Т-90, в Ливии комплекса «Панцирь-С»), что по своей сути является антирекламой российского оружия. Умение работать с заказчиком честно способствует установлению долговременных доверительных отношений. Это особенно важно при работе на внешних рынках, но и при работе на внутреннем рынке при выполнении ГОЗ необходимо организовывать качественное послепродажное обслуживание, обеспечивая бесперебойное функционирование $\mathrm{BB}(\mathrm{C}) \mathrm{T}$ и своевременный ремонт и восстановление. 
Применение внешнеполитическими оппонентами санкций как против отдельных предприятий, так и против целых кластеров ОПК, вопервых, ограничивает возможности по закупке и применению современных технологий и оборудования, что увеличивает издержки и соответственно рост стоимости $\mathrm{BB}(\mathrm{C}) \mathrm{T}$ и приводит к выпуску продукции, не отвечающей современным требованиям, во-вторых, уменьшает количество желающих вкладывать деньги в ОПК или в компании, производящие продукцию двойного назначения.

Серьезной проблемой при формировании благоприятного инвестиционного климата может стать квалификация работников ОПК, их качественный и количественный состав. В России только в 2018 году остановлена тенденция повышения среднего возраста работников обороннопромышленного комплекса, который в настоящее время составляет 46 лет. При этом за 8 лет (с 2012 по 2020 годы) доля молодёжи до 35 лет среди работников ОПК возросла с 20 до более чем 30\% и продолжает расти. Доля ученых и инженеров в структуре российского ОПК составляет $22 \%$ руководителей-управленцев - $15 \%$, рабочих - более $63 \%$. Общая численность работников, занятых в организациях ОПК, составляет около 2 миллионов человек. По первому показателю Россия в три раза отстает от США, в которых доля ученых и инженеров составляет $60 \%$ от числа работников американского военно-промышленного комплекса. Высокий уровень роботизации и применения наисовременнейших технологий позволяет руководству ВПК США качественно изменять структурный состав работников, уменьшая количество рабочих.

Подводя итоги отметим, что основными проблемами, препятствующими формированию благоприятного инвестиционного климата в сфере российского оборонно-промышленного комплекса, являются:

- недостаточность производственных мощностей;

- низкий уровень инновационного потенциала;

- невысокий уровень подготовки управленческих кадров на предприятиях ОПК;

- репутационные потери российского ОПК;

- санкционное давление;

- выбор направлений кадровой политики.

Определение и выбор решений названных проблем, препятствующих формированию благоприятного инвестиционного климата в сфере российского оборонно-промышленного комплекса, не является целью данной статьи и будет выполнено в последующих публикациях.

\section{Литература}

1. Быстров А.В., Пименов В.В. Стратегия экономической и информационной безопасности ОПК - важнейшие компоненты национальной безопасности России// Сборник материалов круглого стола «Современный миропорядок и его влияние на национальную безопасность Российской Федерации».- М.: ВАГШ ВС РФ, 2020 - 611 с. 
2. Гасанбеков С.К., Зобанова М.А., Горохова А.Е. Формирование конкурентоспособности предприятия на основе ресурсного потенциала // Экономика и предпринимательство. 2014. № 11-3 (52). С. 444-446.

3. Голубев С.С., Горбунова В.В., Ефремов А.А. Методика отбора приоритетных технологий для развития производственно-технологической базы предприятий ОПК России // Научный вестник оборонно-промышленного комплекса России. 2019. № 4. C. 24-29.

4. Горохова А.Е. Совершенствование процесса стратегического управления промышленным предприятием // МИР (Модернизация. Инновации. Развитие). 2015. Т. 6. № 2-1 (22). - C. 102-107.

5. Ефремов А.А. Лизинговые отношения в формировании цепей поставок // Проблемы современной экономики. 2011. № 1 (37). - С. 145-148.

6. Зотов А.Н., Горохова А.Е. Развитие инновационного предпринимательства в России // Известия МГТУ МАМИ. 2013. Т. 1. № 4 (18). - С. 204-209.

7. Калугина И.И. Проблемы формирования инвестиционного климата в Российской Федерации // Экономика и менеджмент инновационных технологий. 2013. № 12 [Электронный pecypc]. URL: http://ekonomika.snauka.ru/2013/12/3593 (дата обращения: 29.01.2021).

8. Подберезкин А.Н. Результаты работы Центра военно-политических исследований МГИМО в сотрудничестве с ВАГШ ВС РФ // Сборник материалов круглого стола «Итоги и перспективы профессионального сотрудничества Военной академии Генерального штаба Вооруженных Сил Российской Федерации с ведущими вузами и научно-исследовательскими организациями Российской Федерации. - М.:ВА ГШ ВС РФ, 2020. - $111 \mathrm{c}$.

9. Прохоров Р.Е. Международное военное сотрудничество России со странами Южной Азии // Сборник материалов круглого стола «Современный миропорядок и его влияние на национальную безопасность Российской Федерации».- М.: ВАГШ ВС РФ, 2020. $-611 \mathrm{c}$.

10. Россия в современном геополитическом пространстве: коллективная монография / Под общей редакцией С.В. Кураленко. - М.: ВАГШ ВС РФ, 2017. - 208 с.

11. Чирихин С.Н. Ключевые проблемы формирования благоприятного инвестиционного климата России // Развитие территорий. - 2020. - № 1(19). - С. 23-29.

12. Шпалтаков В.П. Проблемы улучшения инвестиционного климата в России // Вестн. Ом. ун-та. Сер. «Экономика». - 2018. - № 1 (61). - С. 56-66.

Поступила в редакиию

15.02.2021

Сингилевич Дмитрий Александрович - кандидат военных наук, доцент, полковник запаса, руководитель секции правовых проблем обороны государства, заместитель руководителя Экспертного совета Комитета Государственной Думы Российской Федерации по обороне, г. Москва, Россия.

Singilevich Dmitriy Al. - Cand. Sc. (Military), associate Professor, reserve Colonel, Head of the Legal Problems of State Defense Section - Deputy Head of the Expert Council of the State Duma Committee on Defense, Moscow, Russia. 
Секерин Владимир Дмитриевич - доктор экономических наук, професcop, главный научный сотрудник ИПУ РАН, г. Москва, Россия.

Sekerin Vladimir Dmitriyevich - Doctor of Economics, professor, chief researcher in V.A. Trapeznikov Institute of Control Sciences of Russian Academy of Sciences, Moscow, Russia.

Россия, 117997, Москва, ул. Профсоюзная, 65

65, str. Profsoyuznaya, Moscow, 117997, Russia

e-mail: dsingilevich@yandex.ru

e-mail: bcintermarket@yandex.ru 